\title{
EPIDEMIC REITER'S SYNDROME FOLLOWING AN OUTBREAK OF SHIGELLOSIS
}

\author{
M. FINCH*1 \\ G. RODEY ${ }^{2}$ \\ D. LAWRENCE 3 \\ P. BLAKE 1 \\ ${ }^{1}$ Enteris Diseases Branch, Division of Bacterial Diseases. Center for Infectious Diseases \\ (currently with Center for Vaccine Development University of Maryland, Baltimore, MD). \\ Centers fos Disease Control, Atlanta, Georgia 30333 \\ 2 American Red Cross and Washingthon University School of Medicine, St. Louis, Missouri. \\ ${ }^{3}$ Division of Host Factors, Center for Infectious Diseases, Atlanta, Georgia.
}

Key words: Reactive arthritis - Reiter's syndrome - Shigella - Shigella flexneri $2 a$

We prospectively studied the occurrence of Reiter's syndrome (RS) or reactive arthritis (ReA) in 205 of 349 cruise-ship passengers who attended a buffet ashore and developed Shigella flexneri $2 a$ enteritis. Five passengers probably had RS/ReA and 16 were possible or doubtful cases of RS/ReA. HLA-B27 was identified in 4 of 5 probable RS cases, but was not present in any of the 16 possible or doubtful cases nor in any of 20 passengers (controls) without any symptoms of RS/ReA. There was no statistically significant difference in the frequency of B7-Creg antigens in persons with possible or doubtful RS/ReA $(9 / 16)$ compared to controls $(8 / 20)$.

\section{INTRODUCTION}

During World War I, French and German physicians observed that 1 to 3 week after an episode of dysentery, certain soldiers developed a triad of arthritis, urethritis, and conjunctivitis $(8,13)$ which has become known as Reiter's syndrome. Reiter's syndrome is now felt to be part of a group of diseases which included reactive arthritis withouth extraarticular inflammatory manifestations, and perhaps anterior uveitis $(3,4,6)$. The association of HLA-B27 with RS led to a resurgence of interest in this disease and has been felt to represent a potential key to understanding a host of other, closely related HLA-B27-associated disorders (5, $7,11)$. However, just as there is a spectrum of disease manifestations, not all patients with RS are B27-positive. It has been suggested that other HLA markers, particularly the HLA-B CREG group, may be associated with disease $(2,10)$. Therefore, association of specific post-infection inflammatory sequelae with the various HLA types needs better definition.

The occurrence of RS has been well documented to occur following infection by a variety of enteric pathogens such as Shigella, Campylobacter, and Yersinia and certain sexually transmitted diseases $(1,12,15,18)$. For these enteric pathogens, the occurrence of a few outbreaks involving large numbers of infected persons have allowed investigators to carefully document epidemiologic and clinical features of RS in population of known size and onset of infection.

Because enteric disease outbreaks offer the best opportunity to examine epidemiologic and immunologic aspects of RS, we undertook an investigation of post-infections inflammatory sequelae in 205 passengers who developed shigellosis during a 1-week pleasure cruise.

\footnotetext{
* Corresponding author.
} 


\section{METHODS}

In December 1982, 205 of 737 persons aboard a 1-week Caribbean pleasure cruise developed diarrhea caused by Shigella flexneri $2 \mathrm{a}$. Illness was associated with eating at a buffet served ashore in Puerto Plata, Dominican Republic, on the third day of the cruise ( $p<.05$, Fisher's exact test, 2-tailed). Five of 7 ill passengers from whom rectal swabs were obtained while aboard ship had $S$. flexneri in their stools, and an additional 31 of 43 passengers known to have had their stools cultured after the cruise reported that Shigella was recovered.

Two months after the cruise, a screening questionnaire was sent to the ill (205) and well (139) passengers who had attended the implicated buffet, asking them about symptoms associated with post-infectious inflammatory sequelae such as RS. Passengers who indicated that they had had one or more of these symptoms within 6 weeks after their diarrheal illness wene then contacted by telephone to collect more precise information about their symptoms. Physicians of passengers with symptoms consistent with postinfectious inflammatory sequelae were then contacted for clinical information that might support or refute this diagnosis. Patients with post-infectious inflammatory sequelae were classified as probable RS (category 1), possible RS (category 2) and doubtful RS (category 3). Criteria for category 1: (a) patients reported new symptoms and signs of inflammation involving weight bearing joints with or without other sites of inflammation or (b) acute polyarthritis of any joints diagnosed by a physician. Criteria for category 2 : patients reported (a) new symptoms and/or signs of inflammation in any non-weight bearing joints without physician documentation or (b) new symptoms and/or signs of inflammation at two or more extra-articular sites: urethra, eye, and mucocutaneous surfaces. Category 3 : patients only reported new symptoms and/or signs of eye inflammation. Symptoms and signs in all categories had to occur within 6 weeks after the diarrheal illness to be compatible with RS.

HLA typing was completed on all 21 passengers with post-infectious inflammatory sequelae and an additional 20 diarrhea-affected, race-matched passengers without inflammatory sequelae (controls). The 20 controls included spouses of casepatients $(10)$, fellow passengers named by casepatients ( 3 ), and randomly-selected passengers (7). Persons who were blood relatives of case-patients were excluded from the control group.

* B7-CREG antigens are B7, B13, B22, B27, B40 $(60,61)$, B42.

$\because *$ One case was $\mathrm{B} 60,-$ and another was B7, - . These cases are probably homozygous for $\mathrm{B} 60$ and $\mathrm{B} 7$, respectively; however, one cannot be sure without HLA typing the natural parents of these persons.

\section{RESULTS}

One hundred seventy-five $(85 \%)$ of 205 passengers who had had diarrhea and $82(59 \%)$ of 139 well passengers returned the RS questionnaire. Fifty of the ill passengers with diarrhea and 6 of the well passengers reported one or more symptoms known to occur with RS. However, after questioning these passengers over the telephone about their symptoms and collecting additional information from their physicians, only $21(12 \%)$ of the passengers with diarrhea and 2 $(2.4 \%)$ of the well passengers were considered by us to have had one or more symptoms associated with RS or reactive arthritis. These 21 passengers were grouped into 3 categories based on compatibility of clinical information with RS or reactive arthritis: 5 in category 1 (probable RS), 12 in category 2 (possible RS), and 4 in category 3 (conjunctivitis alone). HLA-B27 antigen was present in 4 of 5 persons classified as probable RS (category 1), none of the 16 persons in the other two categories $(\mathrm{p}<.001$, Fisher's exact test, 2 -tailed), and none of 20 controls ( $p<.001$, Fisher's exact test, 2-tailed) (Table 1). There was no significant difference in the number of persons with HLA-B7-CREG* antigens in categories 2 and 3 $(9 / 16)$ compared with controls $(8 / 20)(\mathrm{p}=.503$, Fisher's exact test, 2-tailed).

T A B L E. 1.

Distribution of HLA-B27 antigen in persons classified by compatibility of clinical information with RS and in RS-free persons (controls).

\begin{tabular}{lrcc}
\hline \multicolumn{1}{c}{ Clinical Status } & \multicolumn{3}{c}{ HLA-B27 } \\
& $\begin{array}{c}\text { nega- posi- } \\
\text { tive }\end{array}$ & tive & $\%$ \\
\hline Definite/probable RS (category 1) & 1 & 4 & $80 \%$ \\
Possible RS (category 2) & 12 & 0 & 0 \\
RS doubtful (category 3) & 4 & 0 & 0 \\
Controls & 20 & 0 & 0 \\
\hline
\end{tabular}

HLA-B27 and another B7-CREG antigen were present in two $(40 \%)$ of the 5 persons classified as probable cases of RS (category 1), while 2 B7CREG antigens other than B27 were present in probably:* $3(25 \%)$ of 12 classified as possible cases (category 2), and in $1(25 \%)$ of 4 classified as doubtful, but in only $2(10 \%)$ of 20 controls (Table 2). Persons in category 1 with $\mathrm{B} 27$ and another B7-CREG marker did not have more severe symptoms than those in category 1 with only B27 antigen. However, one person in category 2 who had 2 B7-CREG antigens (B7, B60) had early onset of joint and urinary symptoms ( 4 days after onset of diarrhea) and has had a history of chronic arthritis and dysuria for many years. Furthemore, 
TABLE 2.

Age, sex, race and HLA typing information on persons classified by compatibility of clinical information with RS.

\begin{tabular}{|c|c|c|c|c|}
\hline $\begin{array}{c}\text { Clinical } \\
\text { Status }\end{array}$ & Age & Sex & Race & $\begin{array}{l}\text { B7-CREG } \\
\text { Antigens*** }\end{array}$ \\
\hline \multicolumn{5}{|c|}{ Category* 1: } \\
\hline 1. & 70 & $\mathbf{M}$ & W & B7, B27 \\
\hline 2. & 67 & $M$ & W & B27 \\
\hline 3. & 48 & $M$ & W & B27 \\
\hline 4. & 31 & $\mathrm{~F}$ & W & $\mathrm{B} 27, \mathrm{~B} 60$ \\
\hline 5. & 25 & $\mathrm{~F}$ & W & none \\
\hline \multicolumn{5}{|c|}{ Category 2: } \\
\hline 6. & 78 & $\mathbf{M}$ & W & B7 \\
\hline 7. & 61 & M & W & B7, B- \\
\hline 8. & 60 & $\mathrm{~F}$ & W & $\mathrm{B} 60,-$ \\
\hline 9. & 56 & F & W & $\mathrm{B} 60$ \\
\hline 10. & 50 & $\mathrm{~F}$ & W & $\mathrm{B} 7, \mathrm{~B} 60$ \\
\hline 11. & 48 & $\mathrm{~F}$ & W & $\mathrm{B} 13$ \\
\hline 12. & 33 & $F$ & W & B7 \\
\hline 13. & 22 & $\mathrm{~F}$ & A & B61 \\
\hline 14. & 63 & F & B & none \\
\hline 15. & 58 & $\mathrm{~F}$ & W & none \\
\hline 16. & 44 & F & A & none \\
\hline 17. & 26 & F & $\mathrm{H}$ & none \\
\hline \multicolumn{5}{|c|}{ Category 3: } \\
\hline 18. & 23 & $F$ & W & $\mathrm{B} 60, \mathrm{~B}-$ \\
\hline 19. & 55 & F & W & none \\
\hline 20. & 27 & F & $\mathrm{H}$ & none \\
\hline 21. & 25 & $\mathrm{~F}$ & W & none \\
\hline
\end{tabular}

${ }^{*}$ Category $1=$ probable RS; Category $2=$ possible RS; Category $3=$ doubtful RS.

*Race: $\mathrm{H}=$ Hispanic, $\mathrm{W}=$ White, $\mathrm{B}=$ Black, $\mathrm{A}=$ Asian.

$* * * \mathrm{~B} 7$ cross-reactive antigens (B7-CREG) are B7, $\mathrm{B} 13, \mathrm{~B} 22, \mathrm{~B} 27, \mathrm{~B} 40(60,61), \mathrm{B} 42$.

her father, now deceased, had a history of recurrent arthritis with low back involvement (? sacroiliitis) as a young man.

Clinical characteristics of the 5 persons classified as probable cases of RS are presented in Table 3. Three of the 4 HLA B27-positive persons in this category were in their 5th, 7th, and 8th decades of life, yet this represented their first episode of RS or reactive arthritis. For 1 of the 3 persons, antimicrobial treatment with a cephalosporin to which the organism was sensitive was started on the 7th day of illness and continued for 12 days. For the other 4 persons in category 1 , no antimicrobial treatment was prescribed during the diarrheal illness; however, 2 of the 4 persons subsequently received antimicrobials for symptoms of RS.
Two of the 4 HLA-B27-positive persons were initially diagnosed as having other rheumatologic illnesses, such as paraneoplastic syndrome from prostate carcinoma in one case and ulcerative colitis in another. The person with the latter diagnosis underwent a course of therapy with steroids and sulfasalazine before the correct diagnosis was made.

\section{DISCUSSION}

We examined the rate of post-infectious inflammatory sequelae in persons with diarrhea and determined that approximately $2 \%$ to $3 \%$ of persons with shigellosis probably developed RS, a percentage consistent with the results of two other investigations of racially similar populations affected by Shigella outbreaks $(7,16)$. As have other investigators, we found that $80 \%$ of persons that we classified as probable RS were HLA-B27positive $(7,16)$.

Recently it has been suggested that, in addition to $\mathrm{B} 27$, other $\mathrm{B}$-locus antigens belonging to the B7 serologic cross-reactive group (B7-CREG) might be associated with RS or an incomplete form of RS following enteric infection $(2,10)$. However, none of the 5 persons in our probable RS group had only a non-B27 B7-CREG antigen present. Furthermore, we found little difference in the frequency of B7-CREG markers in controls and in persons who we thought might represent incomplete or atypical RS (categories 2 and 3 ). In addition, we found no increased severity of inflammatory illness in persons in category 1 who had HLA-B27 and another B7-CREG antigen. One person in category 2 who had 2 B7-CREG antigens by HLA typing had a history of recurrent arthritis and dysuria, and her onset of post-shigellosis inflammatory sequelae was unusually rapid. She may have had RS for many years which was exacerbated by this episode of shigellosis; RS can recur in persons re-exposed to certain infectious agents, or it can pursue a chronic course unrelated to any known recurrent infections $(7,14)$.

RS is often described as a disease that predominantly affects young white men in their 20 s and 30s. In our study, the number of persons with RS was too small to reach definite conclusions about the male: female ratio. Two of the $5 \mathrm{RS}$ cases were in women, but only 1 of the 2 was HLA-B27 positive. Young men may have predominated in many previous studies because these were conducted in military populations or because certain symptoms such as urethritis or vaginitis may be less prominent in women (16). This impression tends to be reinforced in clinical practice if the diagnosis is not considered in women presenting with certain symptoms. 
T A B LE 3. - Clinical information on and HLA type of persons classified as probably having Reiter's syndrome (category 1).

\begin{tabular}{|c|c|c|c|c|c|c|c|c|c|c|c|}
\hline Case & Age & Sex & Race & $\begin{array}{l}\text { I.P. } \\
\text { for RS } \\
\text { (days) }\end{array}$ & Fever & $\begin{array}{r}\text { Sympto } \\
\text { Joints }\end{array}$ & $\begin{array}{l}\text { ms of infl } \\
\text { Urethra }\end{array}$ & $\begin{array}{l}\text { mmation } \\
\text { Eyes }\end{array}$ & B27 & $\begin{array}{l}\text { ILA } \\
\text { B7-CREG }\end{array}$ & Physical Findings \\
\hline 1 & 70 & $\mathbf{M}$ & W & 13 & yes & yes & yes & no & + & $\begin{array}{l}A \\
\mathrm{a} \\
\mathrm{j} \\
\mathrm{I} \\
\mathrm{t} \\
\mathrm{c} \\
\mathrm{a}\end{array}$ & $\begin{array}{l}\text { Acute arthritis of kness } \\
\text { ankles elbows, mtp* \& mcp } \\
\text { joints, and circinate balantitis } \\
\text { Initial diagnosis: paraneop'as } \\
\text { tic syndrome due to prostate } \\
\text { carcinoma vs. rheumatoid } \\
\text { arthritis. }\end{array}$ \\
\hline 2 & 67 & $M$ & W & 10 & yes & yes & no & no & + & - & $\begin{array}{l}\text { Acute arthritis of the knees } \\
\text { and mcp joints. Initial diag } \\
\text { nosis: ulcerative colitis. }\end{array}$ \\
\hline 3 & 48 & $\mathbf{M}$ & W & 20 & yes & yes & no & no & + & $\begin{array}{l}A \\
c \\
c \\
1 \\
j \\
t\end{array}$ & $\begin{array}{l}\text { Acute arthritis of the knees } \\
\text { ankles, elbows, mcp joints and } \\
\text { right temporal - mandibular } \\
\text { joint. Initial diagnosis: reac } \\
\text { tive arthritis. }\end{array}$ \\
\hline 4 & 31 & $\mathrm{~F}$ & W & 16 & yes & yes & yes & yes & + & $\begin{array}{l}A \\
\mathrm{~s} \\
\mathrm{r} \\
\mathrm{y} \\
\mathrm{a} \\
\mathrm{c}\end{array}$ & $\begin{array}{l}\text { Acute polyarthritis of the } \\
\text { sacroiliac joints, hips, ankles } \\
\text { mcp, pip } \text { dip*", \& mtp joints }^{*} \text { vaginal discharge, skin rash } \\
\text { and mouth ulcers Initial } \\
\text { diagnosis: RS. }\end{array}$ \\
\hline 5 & 25 & $\mathrm{~F}$ & W & 32 & yes & yes & yes & no & - & $\begin{array}{l}\mathrm{I} \\
1 \\
\mathrm{I}\end{array}$ & $\begin{array}{l}\text { Low back pain, pain in both } \\
\text { hips, swelling and pain in } \\
\text { small joints of the hands } \\
\text { Family history of arthritis. }\end{array}$ \\
\hline
\end{tabular}

- I.P. = incubation period.

${ }^{*} \mathrm{mtp}=$ metatarsal phalangeal, mcp $=$ metacarpal phalangeal, dip $=$ distal interphalangeal, pip $=$ proximal intrephalangeal.

In this study, one person had received antimicrobial therapy during his diarrheal illness, but still developed RS. However, antimicrobial therapy was not prescribed until the 7th day after onset of diarrheal illness, which may have been too late to exert any preventive effect that antimicrobials may have on RS. To our knowledge, no study has examined the effect of antimicrobials on the development of enteritis-associated RS. One report has suggested that antimicrobial therapy does not appear to prevent development or re- currence of RS associated with sexually transmitted diseases (9).

The relationship between HLA-B27 and RS is poorly understood. Specific HLA factors may be directly involved in disease susceptibility or may be linked with other unknown factors that determine susceptibility (17). The absence of HLAB27 and other B7-CREG markers in some persons with typical RS suggests that other, not yet indentified, susceptibility markers may be involved. 


\section{REFERENCES}

1. Aho K., Ahvonen P., Lassus A., Sievers $K$. and Tiilikainen A. (1974): HL-A27 in reactive arthritis: A study of Yersinia arthritis and Reiter's disease. -Arthritis Rheum., 17: 521-526.

2. Arnett F.C., Schacter B.Z., Hochberg M.C. and Bias W.B. (1977): HLA-B7 cross-reactive antigens in B27-negative Reiter's syndrome (abstract). Arthritis Rheum., 20: 106.

3. Brewerton D.A., Caffrey M., Nicholls A., Walters D. and James D.C.O. (1973): Acute anterior uveitis and HL-A27. - Lancet, ii: 994-996.

4. Brewerton D.A., Caffrey M., Nicholls A., Walters D. and James D.C.O. (1974): Acute anterior uveitis and HL-A27. - Lancet $i: 464$.

5. Brewerton D.A., Caffrey M., Nicholls A., Walters D., Oates J.K. and James D.C.O. (1973): Reiter's disease and HL-AW27. - Lancet, ii: 996-998.

6. Calin A. (1981): Reiter's syndrome. In: Kelley W.N., Harris E.D., Ruddy S., and Sledge C.B. (eds). Textbook of Rheumatology. - 1st edition. W.B. Saunders Company, Philadelphia, pp. 1033-1046.

7. Calin A. and Fries J.F. (1976): An " experimental» epidemic of Reiter's syndrome revisited. - Ann. Intern. Med., 84: 564-566.

8. Fiessinger $N$. and Leroy $E$. (1916): Contribution a l'etude d'une epidemie de dysenterie dans le somme. - Bull. Soc. Med. Hop. Paris, 40: 2030.

9. Ford D. (1979): Antibiotic treatment in Reiter's syndrome. - Ann. Rheum. Dis., 38 (suppl.): 98-99.

10. Kaslow R.A., Calin A., Simon D.G., Herman W.H., Barnett $M$. and Rosenbaum J. (1980): Reiter's syndrome and reactive arthritis following Salmonella heidelberg gastroenteritis (abstract). - Arthritis Rheum., 23: 702.

11. Morris R., Metzger A.L., Bluestone R. and Terasaki P.I. (1974): $H L-A 27$ - A clue to the diagnosis and pathogenesis of Reiter's syndrome. - N. Engl. J. Med., 290: 554-556.

12. Noer H.R. (1966): An «experimental» epidemic of Reiter's syndrome. - JAMA 197: 693-698.

13. Reiter H. (1916): Ueber eine unbekannte Spirgchaeteninfektion (Spirochaetosis arthritis arthritica) . - Deutsche Med. Wschr., 42: 1435.

14. Sairanen E., Paronen I. and Mahonen H. (1969): Reiter's syndrome. A follow-up study. - Acta Med. Scand. 185: 57-63.

15. Schacter J. (1974): Can chlamydial infections cause rheumatic disease? In: Dumonde D.C. (ed). Infections and Immunology in the rheumatic diseases. 1st Edition. Blackwell Scientific Publications, Oxford, pp. 521-526.

16. Simon D.G., Kaslow' R.A., Rosenbaum J., Kaye R.L. and Calin A. (1981): Reiter's syndrome following epidemic shigellosis. - J. Rheumatol, 8: 969-973.

17. Solheim B.G., Ryder L.P. and Svejgaard A. (1982): HLA and disease associations. In: Ferrone S. and Solheim B.G. (eds). HLA Typing: Methodology and Clinical Aspects. - 1st Edition, Vol. 2. CRC Press, Boca Raton, FL. pp. 167-175.

18. Van de Putte L.B.A., Berden J.H.M., Boerbooms A.M.T., Muller W.H., Rasker J.I., ReynvaanGroenäijk A.N.K. and van der Linden S.M.J.P. (1980): Reactive arthritis after Campylobacter jejuni enterilis. - J. Rheum., 7: 531-535. 